\title{
Effect of Sustained Release Polymers on Drug Release Profile of Aceclofenac Tablets- Physicochemical Properties, Analysis of Kinetics and Fit Factor
}

\author{
Uzair Nagra', Sherjeel Adnan', Sana Shafqat', Maryam Shabbir ${ }^{1 *}$, Sajid Ali ${ }^{1,2}$, Anum Zafar, \\ Syed Saeed ul Hassan', Javed Iqbal ${ }^{1}$ \\ ${ }^{1}$ Faculty of Pharmacy, University of Lahore, Lahore, PAKISTAN. \\ ${ }^{2}$ Department of Pharmaceutical Technology and Biopharmaceutics, Philipps University, Marburg, GERMANY.
}

\begin{abstract}
Aim: The sustained release tablets of Aceclofenac were prepared and evaluated for the sustained release drug profile with an aim to reduce dosing frequency and provide patient compliance. Materials and Method: The tablets were prepared by using different percentages of Kollidon SR, Carbopol 934P and Eudragit L100 and their combination thereof by wet granulation method. The tablets were analyzed for post compression studies including thickness, diameter, mechanical strength and uniformity of content. The in vitro dissolution studies were carried out in $\mathrm{pH} 1.2$ for first $2 \mathrm{~h}$ and in $\mathrm{pH} 6.8$ buffer for total of $12 \mathrm{~h}$. Results: The tablets exhibited acceptable physicochemical characteristics as per USP limits. The formulation containing Eudragit L100 failed to give the desired sustained release effect where as a slow drug release was observed in formulations containing Carbopol 934P. Therefore, a combination of $\mathrm{pH}$ dependant polymer (Eudragit L100) and $\mathrm{pH}$ independent polymer (Carbopol 934P) combination was used. The formulations were also prepared by Carbopol 934P with plastic polymer (Kollidon SR). The desired sustained release effect was given by latter combination at 2:1 concentration. Conclusion: This formulation, U13, followed zero order kinetics with nonFickian drug release mechanism. When compared to the marketed brand by fit factor, U13 gave the $f 2$ value greater than 50 indicating closer proximity to the approved brand.
\end{abstract}

Key word: Aceclofenac, Fit factor, Kinetics, Carobopol, Kollidon, Eudragit L100.

\section{INTRODUCTION}

Aceclofenac is a Nonsteroidal Anti-inflammatory Drug (NSAID) which is considered as the first-line therapy in the symptomatic treatment of osteoarthritis and rheumatoid arthritis. Aceclofenac has short half-life of four hour and require frequent dosing. The successful treatment of arthritis depends in the maintenance of effective concentration of drug in the body by means of a sustained drug delivery system. ${ }^{1,2}$ Among the different approaches to achieve sustained drug delivery system, matrix tablets prepared by wet granulation method still appears as most efficient method in terms of process development and economy. ${ }^{3}$ Various polymers have been used to retard the release of drug from matrix system. These polymers may include hydrophilic matrices, hydrophobic moieties and plastic matrix system.

The hydrophilic polymer develops a highly viscous gel surface barrier when they are exposed to aqueous medium. This gelatinous barrier controls the liquid penetration into the center of the matrix system and in turn controls the drug release. The hydrophobic polymers are potentially erodible material and control the drug release by pore formation and erosion. On the other hand
Submission Date: 12-06-2018; Revision Date: 24-10-2018; Accepted Date: 18-01-2019

DOI: 10.5530/ijper.53.2s.49 Correspondence:

Ms. Maryam Shabbir, Faculty of Pharmacy, University of Lahore, Lahore, PAKISTAN.

Phone: +92 3454740763

E-mail: maryam.shabbir@ pharm.uol.edu.pk

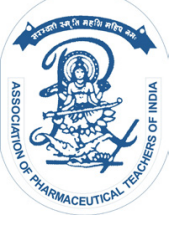

www.ijper.org 
the plastic system forms insoluble matrices and liquid penetration into the matrix is the rate limiting step in such systems unless channeling agents are employed in the matrix system. ${ }^{4}$

The objective of the present study was to evaluate the efficiency of above mentioned polymers to sustain the release rate of aceclofenac and to reduce the dosing frequency to improve patient compliance. Carbopol 934P (hydrophilic polymer), Kollidon SR (plastic matrix) and Eudragit L100 (hydrophobic polymer) were evaluated for their physicochemical properties and potential sustain release effect at different concentration independently and in possible combination with each other. The formulations were also evaluated with the marketed product of aceclofenac sustained release product (hereby denoted as Brand-A) by means of model independent approach (fit factor) as approved by the FDA. ${ }^{5}$

\section{MATERIALS AND METHOD}

\section{Materials}

Aceclofenac (donated by Medisearch Pharma, Lahore, Pakistan); Carbopol 934P (Corel Pharma Chem., India); Kollidon SR (BASF, Germany); Eudragit L100 (Merck, Germany); lactose (FDA foremost, USA); polyvinylpyrrolidone (Saad traders, Lahore); isopropyl alcohol (City corporation, Lahore); magnesium stearate (Wilfrid Smith Ltd, UK); potassium dihydrogen phosphate (Fluka, Germany); potassium hydroxide (Aldrich Chemicals Co. Ltd.); $\mathrm{HCl}$ (BDH, England); R.O water

\section{Method}

\section{Preparation of matrix sustained tablet of aceclofenac}

For the development of matrix tablet of aceclofenac by wet granulation method accurately weighed amount of diluent (lactose) and binder (PVP K-30) were added in the mortar followed by matrix forming polymer (Carbopol 934P, Kollidon SR and/or Eudragit L100) after passing them through 40 mesh screen (Table 1). Then drug was added and material was triturated slowly with Isopropyl alcohol (IPA) as solvent to form a dough mass. The wet mass was passed through sieve number 20. The granules were dried in hot air oven at $40^{\circ} \mathrm{C}$ for $60 \mathrm{~min}$. Magnesium stearate was added as a lubricant to the dried granules and blended in a closed polyethylene bag. The tablets were compressed by single punch machine with a punch diameter of $10.8 \mathrm{~mm}$.

\section{Physicochemical properties of sustained release tablets of aceclofenac Thickness and mechanical strength}

The thickness of ten randomly selected tablets were taken from each formulation and measured with digital vernier caliper. Average and standard deviation was calculated by SPSS software. ${ }^{8}$

The mechanical strength of tablet can be determined by hardness and friability. For hardness test, ten tablets were randomly selected from each formulation. The hardness was measured with Monsanto hardness tester. The average was calculated by SPSS software. ${ }^{7}$

For friability test, ten tablets were randomly selected from each formulation and tumbled in a Roche friabilator at $25 \mathrm{rpm}$ for $4 \mathrm{~min}$. Percentage friability was calculated by: ${ }^{8}$

$$
\text { Percentage friability }=\left(\mathrm{W}_{1}-\mathrm{W}_{2}\right) / \mathrm{W}_{1} \times 100
$$

Where, $\mathrm{W}_{1}$ : weight of tablets before test; $\mathrm{W}_{2}$ : weight of tablets after test

\section{Uniformity of mass and uniformity of content}

It can be determined by weight variation and content uniformity. According to USP-NF, twenty tablets were weighed individually on a digital weighing balance. The percent deviation was calculated by the following equation. ${ }^{9}$

Percentage deviation $=\underset{\text { weight } / \text { average } \text { weight }) \times 100}{\text { Average weight }- \text { individual }}$

For content uniformity, the tablets were crushed in mortar and powder equivalent to $100 \mathrm{mg}$ drug was dissolved in $5 \mathrm{ml}$ of methanol $(70 \%)$. The volume was made up to $100 \mathrm{ml}$ with phosphate buffer $\mathrm{pH}$ 6.8. The sample was mixed thoroughly and filtered through whatman filter paper. The solution was suitably diluted and analyzed spectrophotometrically by UV spectrophotometer at $276 \mathrm{~nm} .{ }^{1}$

\section{In vitro dissolution study}

The dissolution study was carried out in USP apparatus II using $\mathrm{pH} 1.2$ for $2 \mathrm{~h}$ and phosphate buffer 6.8 for $2^{\text {nd }}$ to $12^{\text {th }} \mathrm{h}$ as dissolution medium $(900 \mathrm{ml})$. The medium was maintained at $37 \pm 0.5^{\circ} \mathrm{C}$ and paddle was operated at $50 \mathrm{rpm}$. Samples were withdrawn after suitable interval of time over a period of $12 \mathrm{~h}$ and filtered through whatman filter paper before analysis on UV spectrophotometer at $273 \mathrm{~nm} .{ }^{1}$

\section{Release rate kinetic}

In vitro dissolution study was analyzed by model dependent approach by fitting the data in following models. ${ }^{10}$

Zero order equation: $\mathrm{Q}_{\mathrm{t}}=\mathrm{Q}_{0}+\mathrm{K}_{0} \mathrm{t}$

First order equation: $\log \mathrm{Q}_{\mathrm{t}}=\log \mathrm{Q}_{0}+\mathrm{K}_{1} \mathrm{t} / 2.303$

Higuchi equation: $\mathrm{M}_{\mathrm{t}} / \mathrm{M}_{\infty}=\mathrm{k} 2 \sqrt{\mathrm{t}}$

Korsmeyer-Peppas equation: $M_{t} / M_{\infty}=k_{3} t^{n}$ 
Where, $Q_{t}$ : amount of drug dissolved in time $t ; Q_{0}$ : initial amount of drug in the solution; $\mathrm{K}_{0}$ : zero order release constant; $\mathrm{K}_{1}$ : first order release constant; $\mathrm{M}_{\mathrm{t}}$ : cumulative amount of drug released at time $t ; \mathrm{M}_{\infty}$ : absolute cumulative amount of drug released at infinite time; $\mathrm{k}_{2}$ : constant reflecting the design variable of the system; $\mathrm{k}_{3}$ : constant incorporating structural and geometric characteristics of the device; $n$ : release exponent indicative of the mechanism of drug release.

\section{Fit factors $\left(f_{1}\right.$ and $\left.f_{2}\right)$}

The optimized formulation was compared with the commercially available Alkeris-SR (200 mg by Sami Pharmaceuticals, Pakistan) sustained release tablet of aceclofenac referred here as Brand-A. The factor, $f_{1}$, is the average percentage difference over time points in the amount of test batch dissolved as compared to the reference product. The $f_{1}$ is also known as the dissimilarity factor. As the value approaches 0 it signifies that the test and the reference profiles are identical and increases proportionally with the dissimilarity between the two dissolution profiles. It is calculated by the following equation: ${ }^{9}$

$$
\mathrm{f}_{1}=\left\{\frac{\sum_{\mathrm{t}=1}^{\mathrm{n}}\left|\mathrm{R}_{\mathrm{t}}-\mathrm{T}_{\mathrm{t}}\right|}{\sum_{\mathrm{t}=1}^{\mathrm{n}} \mathrm{R}_{\mathrm{t}}}\right\} \times 100
$$

The value of factor $f_{2}$ lies between 0 and 100 . The $f_{2}$ is 100 when the test and the reference profiles are identical and it approaches 0 as the dissimilarity increases. The $f_{2}$ is also known as the similarity factor and is calculated by the following equation: ${ }^{5}$

$$
\mathrm{f}_{2}=50 \log \left[\frac{100}{\sqrt{1+\left(\sum_{\mathrm{i}=0}^{\mathrm{n}}\left(\mathrm{R}_{\mathrm{t}}-\mathrm{T}_{\mathrm{t}}\right)^{2}\right) / \mathrm{n}}}\right]
$$

\section{RESULT AND DISCUSSION}

\section{Thickness and mechanical strength}

The thickness and diameter of tablet is given in Table 2. The low value of S.D. in thickness indicated that the process was reproducible. Tablet thickness is consistent if the tablet granulation is adequately constant in particle size and distribution, punch tooling is of consistent length and tablet press is clean and in good working condition. As the average diameter of all formulations was less than $12.5 \mathrm{~mm}$ thus percentage deviation allowed was $\pm 5 .{ }^{11}$ The diameter of all formulation falls in this limit.
The hardness of the tablets should be between 4 to $6 \mathrm{~kg}$ but for some sustained release tablets the hardness may be between 10 to $20 \mathrm{~kg}^{12}$ Therefore, all the formulations were within the range of acceptable criteria (Table 2). Tablets formulated with Carbopol 934P had increased hardness as compared to Kollidon SR and Eudragit L100 formulations. ${ }^{13}$ Although hardness is an unofficial test yet it can affect the disintegration rate of tablet; if the tablet is too hard it may not disintegrate in the required period of time where as if the tablet is too soft it will not be able to withstand handling during subsequent processing such as packaging. Therefore compliance of hardness is an important criterion for tablets. All the formulations complied with the USP limit i.e. friability was less than $1 \% .^{11}$

\section{Uniformity of mass and uniformity of content}

The result of weight variation and content uniformity are given in Table 2. According to USP; for tablets with total weight of $250 \mathrm{mg}$ or more, the percentage deviation allowed is $\pm 5 \%$. As the percentage deviation was $-2.76 \%$ to $1.40 \%$ range thus all formulation complied with the official criteria. The density of the material and physical dimensions of the tablet determine the weight of the tablet. It is determined to ensure that tablet contain proper amount of drug. The content uniformity of tablets should be in $85 \%$ to $115 \%$ range thus all the formulations complied with the specifications. Weight variation and uniformity of content were used to ensure that tablet contains intended amount of drug substance with little variations. ${ }^{1,14-15}$

\section{Dissolution studies of aceclofenac sustained release tablet \\ Dissolution profile of formulations containing Kollidon SR as polymer}

The cumulative percentage drug release profile of sustain release tablets of aceclofenac containing Kollidon SR as polymer is given in Figure 1. It depicts that increasing the concentration of Kollidon SR decreased the initial release of drug in $1^{\text {st }}$ hour of dissolution. The $t_{50 \%}$ and $t_{90 \%}$ (Table 3) increased for these formulations as the polymer percentage increased. The variable release profile of Kollidon SR was due to composition of polymer; it contains $80 \%$ polyvinyl actete (PVAc) and $19 \%$ povidone that are capable of forming insoluble matrix of PVAc. The water soluble povidone gets dissolved from matrix and forms pores for drug diffusion and dissolution. ${ }^{12}$ Kollidon SR was used for the development of $\mathrm{pH}$ independent sustain release matrix tablet. ${ }^{16,17}$

The drug release profile was fitted in different kinetic models like zero order, first order and Higuchi model and is given in Table 4. The formulations U1, U2 and 


\begin{tabular}{|c|c|c|c|c|c|c|c|c|}
\hline Formulation & $\begin{array}{l}\text { Drug } \\
(\%)\end{array}$ & $\begin{array}{l}\text { Carbopol } \\
\text { 934P (\%) }\end{array}$ & $\begin{array}{c}\text { Kollidon } \\
\text { SR (\%) }\end{array}$ & $\begin{array}{c}\text { Eudragit } \\
\text { L } 100 \\
(\%)\end{array}$ & $\begin{array}{c}\text { Lactose } \\
(\%)\end{array}$ & $\begin{array}{l}\text { PVP } \\
(\%)\end{array}$ & $\begin{array}{l}\text { Magnesium } \\
\text { stearate (\%) }\end{array}$ & $\begin{array}{c}\text { Total } \\
\text { weight } \\
\text { (mg) }\end{array}$ \\
\hline U1 & 40 & & 20 & & 36 & 2 & 2 & 500 \\
\hline U2 & 40 & & 25 & & 31 & 2 & 2 & 500 \\
\hline U3 & 40 & & 30 & & 26 & 2 & 2 & 500 \\
\hline U4 & 40 & 20 & & & 36 & 2 & 2 & 500 \\
\hline U5 & 40 & 25 & & & 31 & 2 & 2 & 500 \\
\hline U6 & 40 & 30 & & & 26 & 2 & 2 & 500 \\
\hline U7 & 40 & & & 20 & 36 & 2 & 2 & 500 \\
\hline U8 & 40 & & & 25 & 31 & 2 & 2 & 500 \\
\hline U9 & 40 & & & 30 & 26 & 2 & 2 & 500 \\
\hline U10 & 40 & & 10 & 20 & 26 & 2 & 2 & 500 \\
\hline U11 & 40 & & 15 & 15 & 26 & 2 & 2 & 500 \\
\hline U12 & 40 & & 20 & 10 & 26 & 2 & 2 & 500 \\
\hline U13 & 40 & 20 & 10 & & 26 & 2 & 2 & 500 \\
\hline U14 & 40 & 15 & 15 & & 26 & 2 & 2 & 500 \\
\hline U15 & 40 & 10 & 20 & & 26 & 2 & 2 & 500 \\
\hline
\end{tabular}

\begin{tabular}{|c|c|c|c|c|c|c|}
\hline \multicolumn{6}{|c|}{ Table 2: Post-compression studies of compressed tablets of Aceclofenac } \\
\hline Formulation & $\begin{array}{c}\text { Thickness } \\
\text { (mm) }\end{array}$ & Hardness (kg) & $\begin{array}{c}\text { Friability } \\
\mathbf{( \% )}\end{array}$ & $\begin{array}{c}\text { Weight } \\
\text { (mg) }\end{array}$ & $\begin{array}{c}\text { Weight } \\
\text { variation (\%) }\end{array}$ & $\begin{array}{c}\text { Content } \\
\text { uniformity (\%) }\end{array}$ \\
\hline U1 & $7.3 \pm 0.05$ & $10.40 \pm 0.42$ & 0.15 & 485.0 & -3.00 & $98.82 \pm 0.04$ \\
\hline U2 & $7.5 \pm 0.07$ & $12.80 \pm 0.85$ & 0.12 & 486.2 & -2.76 & $103.85 \pm 0.02$ \\
\hline U3 & $6.0 \pm 0.09$ & $14.00 \pm 0.52$ & 0.082 & 504.4 & 0.88 & $99.12 \pm 0.08$ \\
\hline U4 & $5.6 \pm 0.11$ & $19.50 \pm 0.74$ & 0.02 & 485.0 & -3.00 & $102.25 \pm 0.06$ \\
\hline U5 & $5.7 \pm 0.08$ & $18.50 \pm 0.21$ & 0.05 & 497.1 & -0.58 & $100.98 \pm 0.05$ \\
\hline U6 & $5.8 \pm 0.04$ & $18.00 \pm 0.15$ & 0.035 & 507.0 & 1.40 & $98.58 \pm 0.09$ \\
\hline U7 & $6.0 \pm 0.10$ & $14.50 \pm 0.74$ & 0.07 & 502.0 & 0.40 & $99.83 \pm 0.04$ \\
\hline U8 & $6.0 \pm 0.05$ & $15.50 \pm 0.15$ & 0.09 & 493.4 & -1.32 & $99.25 \pm 0.08$ \\
\hline U9 & $6.0 \pm 0.08$ & $12.90 \pm 0.25$ & 0.08 & 493.26 & 1.34 & $101.08 \pm 0.06$ \\
\hline
\end{tabular}

\section{Table 3: $t_{50 \%}$ and $t_{90 \%}$, similarity factor and dissimilarity factor of sustained release formulation of Aceclofenac}

\begin{tabular}{|c|c|c|c|c|c|c|c|c|c|c|c|c|c|c|c|c|}
\hline \multirow{2}{*}{ Formulation } & U1 & U2 & U3 & U4 & U5 & U6 & U7 & U8 & U9 & U10 & U11 & U12 & U13 & U14 & U15 & Brand-A \\
\hline $\mathrm{t}_{50 \%}(\mathrm{hr})$ & 4.93 & 5.18 & 5.36 & 5.09 & 5.23 & 5.63 & 5.10 & 4.87 & 4.73 & 4.85 & 5.15 & 5.82 & 5.79 & 5.04 & 4.75 & 4.77 \\
\hline $\mathrm{t}_{90 \%}(\mathrm{hr})$ & 8.87 & 9.32 & 9.65 & 9.16 & 9.42 & 10.14 & 9.17 & 8.77 & 8.52 & 8.72 & 9.27 & 10.48 & 10.42 & 9.07 & 8.55 & 10.5 \\
\hline$f_{2}$ & 24 & 28 & 31 & 26 & 29 & 27 & 11 & 4 & 5 & 13 & 16 & 13 & 77 & 29 & 10 & -- \\
\hline$f_{1}$ & 26 & 22 & 19 & 24 & 21 & 16 & 47 & 63 & 62 & 42 & 37 & 28 & 2 & 21 & 51 & -- \\
\hline
\end{tabular}

U3 followed Higuchi model. This signified that the main diffusion as proportionality between percentage drug drug release mechanism from the polymeric matrix was release and square root of time is regarded as an indicator 


\begin{tabular}{|c|c|c|c|c|c|c|c|c|}
\hline \multirow{2}{*}{ Table 4: Release kinetics of in vitro dissolution of sustained release tablets of Aceclofenac } \\
\hline \multirow{2}{*}{ Formulation } & \multicolumn{2}{|c|}{ Zero Order } & \multicolumn{2}{|c|}{ 1st Order } & \multicolumn{2}{c|}{ Higuchi Model } & \multicolumn{2}{c|}{$\begin{array}{c}\text { Korsmeyer's } \\
\text { Peppas }\end{array}$} \\
\cline { 2 - 9 } & $\mathrm{R}^{2}$ & $\mathrm{~K}_{1}$ & $\mathrm{R}^{2}$ & $\mathrm{~K}_{2}$ & $\mathrm{R}^{2}$ & $\mathrm{~K}_{3}$ & $\mathrm{R}^{2}$ & $\mathrm{n}$ \\
\hline U1 & 0.9501 & 10.141 & 0.8977 & 0.249 & 0.9804 & 29.283 & 0.9818 & 0.54 \\
\hline U2 & 0.9521 & 9.660 & 0.8975 & 0.217 & 0.9623 & 27.667 & 0.9721 & 0.59 \\
\hline U3 & 0.9417 & 9.329 & 0.8948 & 0.195 & 0.9513 & 26.497 & 0.9741 & 0.63 \\
\hline U4 & 0.9512 & 9.831 & 0.8906 & 0.239 & 0.9932 & 28.547 & 0.9925 & 0.50 \\
\hline U5 & 0.9531 & 9.553 & 0.8937 & 0.222 & 0.9909 & 27.668 & 0.9909 & 0.52 \\
\hline U6 & 0.9657 & 8.876 & 0.8894 & 0.184 & 0.9913 & 25.532 & 0.9961 & 0.55 \\
\hline U7 & 0.8684 & 9.811 & 0.9198 & 0.186 & 0.8436 & 26.886 & 0.9428 & 0.85 \\
\hline U8 & 0.8579 & 10.259 & 0.9328 & 0.212 & 0.8715 & 28.498 & 0.9372 & 0.77 \\
\hline U9 & 0.8452 & 10.568 & 0.9340 & 0.232 & 0.8783 & 29.599 & 0.9243 & 0.72 \\
\hline U10 & 0.9213 & 10.317 & 0.9806 & 0.265 & 0.9380 & 29.833 & 0.9351 & 0.54 \\
\hline U11 & 0.9386 & 9.712 & 0.9475 & 0.224 & 0.9869 & 27.887 & 0.9521 & 0.58 \\
\hline U12 & 0.9581 & 8.588 & 0.9209 & 0.168 & 0.9592 & 24.428 & 0.9689 & 0.63 \\
\hline U13 & 0.9966 & 8.635 & 0.9487 & 0.148 & 0.8897 & 23.734 & 0.9926 & 0.86 \\
\hline U14 & 0.9731 & 9.928 & 0.9530 & 0.222 & 0.9805 & 28.362 & 0.9929 & 0.59 \\
\hline U15 & 0.9295 & 10.530 & 0.9321 & 0.305 & 0.9804 & 30.945 & 0.9853 & 0.45 \\
\hline Brand-A & 0.985 & 8.4588 & 0.9116 & 0.1682 & 0.9148 & 29.629 & 0.9707 & 0.98 \\
\hline
\end{tabular}

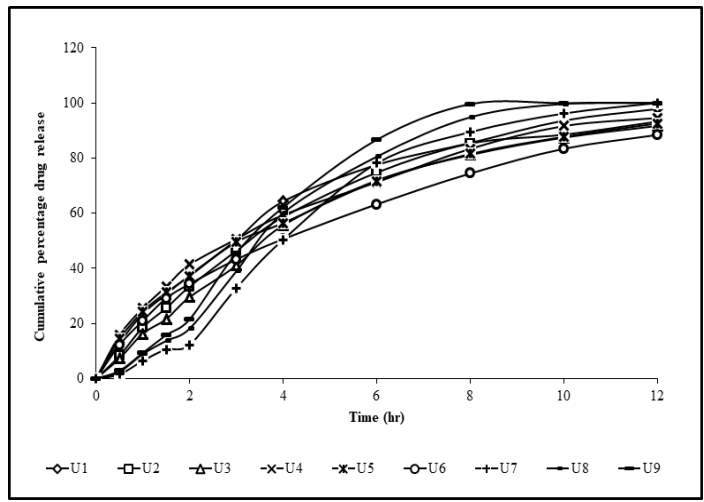

Figure 1: In vitro dissolution of sustained release Aceclofenac tablets of individual polymers

of diffusion controlled drug release. The ' $n$ ' value of Korsmeyer-Peppas equation signified that mechanism of drug release was non-Fickian or anomalous favoring both diffusion and erosion as the values were greater than $0.5 .^{18,19}$

\section{Dissolution profile of formulations containing Carbopol $934 \mathrm{P}$ as polymer}

As the concentration of Carbopol 934P was increased, a decreased release rate effect was seen from U4 to U6 (Figure 1). The time required for $90 \%$ of the drug to be released from U6 at $30 \% \mathrm{w} / \mathrm{w}$ concentration of
Carbopol 934P was beyond $10 \mathrm{~h}$ (Table 3). From Figure 1 it can be observed that drug release was inversely proportional to the level of rate retarding polymer in matrix system i.e. the rate and extent of drug release increases with decrease in total polymer content. During the initial phase of dissolution profile the increase in polymeric content lead to quicker hydration which decreased the rate of drug release from matrix system. ${ }^{4}$ It was due to the formation of gel barrier around the tablet which became stronger with increased concentration of Carbopol 934P. Carbopol 934P polymers are highly effective at low concentration, typically 3-30\%. Due to the anionic nature of the polymer, drug release may be media dependent. As the $\mathrm{pH}$ of the media increases it causes ionization of the $-\mathrm{COOH}$ group which results in maximum swelling and smaller regions of microcavities. This rapid gel formation acts as a barrier and prolongs the drug release. Carbopol 934P polymer has a good matrix forming property and enhances release of poorly soluble drugs in neutral or basic buffers. ${ }^{9}$ Aceclofenac is a water insoluble drug but its solubility is enhanced in phosphate buffer $\mathrm{pH} 6.8$ $(1538.7 \pm 1.215 \mathrm{mcg} / \mathrm{ml})$ thus the dissolution medium favored both the drug release and sustained effect due to polymer. ${ }^{20}$ The $R^{2}$ values of different kinetic models 


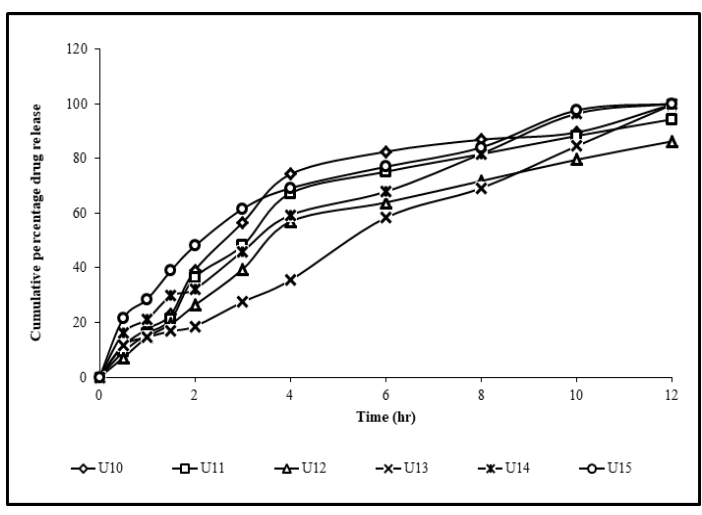

Figure 2: In vitro dissolution of sustained release Aceclofenac tablets with combination of polymers

(Table 4) showed that U4, U5 and U6 followed Higuchi model and the drug release mechanism was non-Fickian. ${ }^{21}$

\section{Dissolution profile of formulations containing Eudragit L100 as polymer}

The cumulative percentage drug release profile of formulations containing Eudragit L100 is shown in Figure 1. The time required for $50 \%$ of the drug release was achieved in less than $2 \mathrm{~h}$ in all formulations containing Eudragit L100 (Table 3). As the concentration of Eudragit L100 was increased it further increased the rapid release of drug from the matrix system. Eudragit L100 is a hydrophobic polymer but the solubility of polymer increases as the $\mathrm{pH}$ increases thus it depicts $\mathrm{pH}$ dependent profile. It has been established that Eudragit L100 dissolves at $\mathrm{pH} \geq 6.0$ upon deprotonation of $-\mathrm{COOH}$ group at alkaline $\mathrm{pH} .{ }^{22}$ As the amount of Eudragit L100 increases, it causes formation of more pores thus creating channels for the dissolution media to penetrate into the matrix system which results in faster dissolution of the drug. ${ }^{23}$ The release behavior from these matrix systems was first order kinetics probably due to irregular erosion process from the matrix. Matrix tablets were thus prepared by using combination of $\mathrm{pH}$ dependent Eudragit with a $\mathrm{pH}$ independent Kollidon SR polymer in different ratios with the aim of attaining more regular and reproducible release profile. ${ }^{24}$

\section{Dissolution profile of formulations containing combination of Kollidon SR and Eudragit L100}

The cumulative percentage drug release of formulations containing combination of Kollidon SR and Eudragit L100 is shown in Figure 2 that depicts that as the concentration of Kollidon SR was increased the retarding effect of Kollidon SR also increased. The time required for $50 \%$ and $90 \%$ of the drug to release from the matrix system increased from U10 to U12 (Table 3). Kollidon SR contains no ionic groups and was inert to the drug

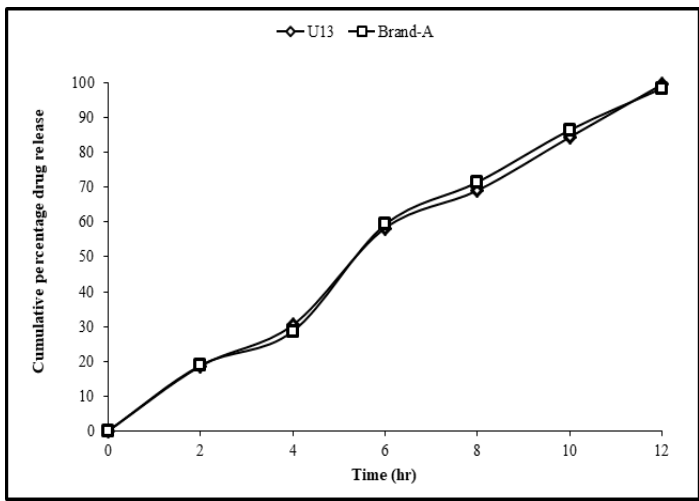

Figure 3: Comparison of U13 with commercially available brand of Aceclofenac sustained release tablet

and dissolution medium thus imparting sustaining effect whereas Eudragit L100 was soluble in basic $\mathrm{pH}$ dissolution medium leading to formation of pore which causes leaching of drug from the matrix. Hence increasing the amount of Eudragit L100 as compared to Kollidon SR lessens the retarding effect of Kollidon $\mathrm{SR}$ in sustained release tablets. ${ }^{25}$ The $\mathrm{R}^{2}$ value of different kinetic models shown in Table 4 indicated that formulation U10 followed first order kinetics. U11 and U12 followed Higuchi model with diffusion controlled drug release. The formulations had non-Fickian diffusion drug release mechanism as the ' $n$ ' value was more than 0.5 and less than 1.0 as shown in Table $4 .{ }^{10}$

\section{Dissolution profile of formulations containing different combination of Kollidon SR and Carbopol 934P}

As the formulations containing Carbopol 934P alone had a slow drug release $\left(t_{90 \%}>12 \mathrm{~h}\right)$, the tablets were formulated containing a combination of hydrophilic (Carbopol 934P) and plastic polymer (Kollidon SR). The cumulative percentage drug release profile of formulations containing combination of Kollidon SR and Carbopol 934P is given in Table 3. As the concentration of Kollidon SR was increased the release rate of drug from the matrix system was faster. This faster release rate was because of lower gel strength, less entanglement and smaller diffusion path length as compared to formulation containing more concentration of Carbopol 934P which has better swelling property in contrast to Kollidon SR. ${ }^{26}$ The $t_{50 \%}$ and $t_{90 \%}$ decreased by decreasing the Carbopol 934P concentration in matrix system with Kollidon SR (Table 3). When fitted in various kinetic models, U13 followed zero order whereas U14 and U15 followed Higuchi model as shown in Table 4. The zero order kinetics signified that the drug release from matrix was independent of concentration whereas Higuchi kinetics signified that the release rate was diffusion 
controlled. The formulations U13 and U14 had anomalous drug release mechanism whereas U15 had Fickian diffusion mechanism. ${ }^{10}$

\section{Fit Factor}

The similarity in the release profile of aceclofenac formulations and marketed tablet, Brand-A, was compared by using model independent approach. The fit factor can be expressed by two approaches i.e. the difference factor $\left(f_{1}\right)$ and the similarity factor $\left(f_{2}\right)$. The $f_{1}$ is proportional to the average difference between the two profiles whereas $f_{2}$ is inversely proportional to the average squared difference between the two profiles. ${ }^{5}$ The dissolution profiles are considered similar if $f_{1}$ is between 0 and 15 whereas $f_{2}$ is between 50 and $100 .^{2}$ In this study the fit factor signified the similarity of the dissolution profile of only U13 with Brand-A with $f_{2}>50$ and $f_{1}<15$ (Table 3 and Figure 3). The formulation U13 containing Carbopol 934P and Kollidon SR (2:1) had similar zero order kinetic profile and non-Fickian drug release mechanism as Brand-A. The least similarity with the reference was observed in formulations containing Eudragit L100.

\section{CONCLUSION}

The formulations made of Kollidon SR, Carbopol 934P, Eudragit L100 and their combination thereof were suitable as matrix forming agents and allowed preparation of sustained release tablets of aceclofenac by wet granulation. The drug release behavior was influenced by the kind and concentration of polymer used and relative w/w ratio of mixtures. Even though the formulations have passed the USP (2012) specifications, most of the formulations were not interchangeable with the marketed product. The present study demonstrated that Carbopol 934P and Kollidon SR, at 20\% and 10\% concentration respectively, provide sustained release matrix system for the formulation of BCS II class drug aceclofenac. This formulation (U13) followed zero order release kinetics with anomalous drug release mechanism.

\section{ACKNOWLEDGEMENT}

Authors would like to thank Faculty of Pharmacy, University of Lahore for providing research facilities.

\section{CONFLICT OF INTEREST}

The authors declare no conflict of interest.

\section{REFERENCES}

1. Mutalik S, Naha A, Usha AK, Ranjith AK, Musmade $\mathrm{P}$, Manoj $\mathrm{K}$, et al. Preparation, in vitro, preclinical and clinical evaluations of once daily sustained release tablets of Aceclofenac. Arch Pharm Res. 2007;3(2):222-34.

2. Ghosh S, Barik B. Preparation and evaluation of aceclofenac sustained release formulation and comparison of formulated and marketed product. International Journal of Medicine and Medical Sciences. 2009;1(9):375-82.

3. Ceballos A, Cirri M, Maestrelli F, Corti G, Mura P. Influence of formulation and process variables on in vitro release of theophylline from directly-compressed Eudragit matrix tablets. II Farmaco. 2005;60(11-12):913-8.

4. Reza MS, Quadir MA, Haider SS. Comparative evaluation of plastic, hydrophobic and hydrophilic polymers as matrices for controlled-release drug delivery. J Pharm Pharmaceut Sci. 2003;6(2):279-91.

5. Yuksel N, Kanık AE, Baykara T. Comparison of in vitro dissolution profiles by ANOVA-based, model-dependent and -independent methods. Int J Pharm. 2000;209(1-2):57-67.

6. Sandhiya AKM, Shanmugam, Vetrichelvan T. Design and development of ambroxol hydrochloride sustained release matrix tablets. International Journal of Pharmacy and Pharmaceutical Sciences. 2011;3(3):200-3.

7. Prajapati B, Patel R, Patel D, Shah P, Chicago. Metformin hydrochloride sustained release tablet using different matrixing tablet. e-Journal of Science and Technology. 2013;8(4)

8. Kulkarni SV, Patel N, Rao BS, Kheni P, Patel P, Annanage A. Formulation and in vitro evaluation of sustained release matrix tablet of zolpidem tartarate. Int J Pharm Tech Res. 2011;3(2):858-63.

9. Islam SM, Islam S, Shahriar M, Dewan I. Comparative in vitro dissolution study of Aceclofenac Marketed Tablets in Two Different Dissolution Media by Validated Analytical Method. Journal of Applied Pharmaceutical Science. 2011;1(9):87-92.

10. Shabbir M, Ali S, Farooq M, Adnan S, Yousaf M, Idrees A, et al. Formulation Factors Affecting in vitro and ex vivo Permeation of Bisoprolol Fumarate from a Matrix Transdermal Patch. Advances in Polymer Technology. 2016;35(3):237-47.

11. Bano R, Gauhar S, Naqvi SBS, Mahmood S. Pharmaceutical evaluation of different brands of levofloxacin tablets $(250 \mathrm{mg})$ available in local market of Karachi (Pakistan). International Journal of Current Pharmaceutical Research. 2011;3(1):15-22.

12. Rehman S, Al-Masum MA, Sharmin F, Islam A, Reza MS. Formulation and Evaluation of Bi-layered Sustained Release Matrix Tablets of Tramadol Hydrochloride. Journal of Applied Pharmaceutical Science. 2012;2(6):129-34.

13. Asaduzzaman M, Elias-Al-Mamun M, Islam MS, Jalil RU. Effect of HPMC 4 Cps and Carbopol 974p NF On Release Kinetics Of Ciprofloxacin From Kollidon® SR Embedded Matrix Tablets. J Pharm Sci Res. 2009;1(4):137-45.

14. Gad SC. Tablet Characterization. Pharmaceutical Manufacturing Handbook: Production and Processes Wiley. 2008;927.

15. Troy DB, Remington JP, Beringer P. Oral solid dosage forms. Remington: The Science and Practice of Pharmacy. 1: Lippincott Williams and Wilkins. 2006;917.

16. Elias-Al-Mamun, Asaduzzaman, Islam S, Reza-ul-Jalil. Effect of hydrophobic excipients on release kinetics of Ciprofloxacin from Kollidon SR embedded matrix tablets. Asian Journal of Pharmaceutical and Clinical Research. 2012;5(3):51-5

17. Saxena A, Srinivas N, Sravanthi M. Formulation and In-vitro Evaluation of Matrix Type Sustained Release Tablets of Paliperidone. Innovations in Pharmaceuticals and Pharmacotherapy. 2013;1(3):185-98.

18. Siepmann J, Peppas NA. Modeling of drug release from delivery systems based on hydroxypropryl methylcellulose (HPMC). Adv Drug Deliv Rev. 2012;64:163-74.

19. Shabbir M, Fazli AR, Ali S, Raza M, Sharif A, Akhtar MF, et al. Effect of hydrophilic and hydrophobic polymer on in vitro dissolution and permeation of bisoprolol fumarate through transdermal patch. Acta Poloniae Pharmaceutica-Drug Research. 2017;74(1):187-97.

20. Ochiuz L, Iulian S, Moscalu M, Popa G, Adrian S, Popovici I. Investigations on the in vitro release mechanism of sodium alendronate from hydrophilic matrix tablets. Farmacia. 2010;58(6):795-805 
21. Ali S, Shabbir M, Shahid N, Amin U, Hamid I, Raza M. Effect of Polysorbate 80 Through Rabbit's Skin Using Transdermal Patch Loaded with Bisoprolol Fumarate as Model Drug. Pakistan Journal of Zoology. 2016;48(1):227-34.

22. Cetin M, Atila A, Kadioglu Y. Formulation and in vitro characterization of Eudragit $₫$ L100 and Eudragit $₫$ L100-PLGA nanoparticles containing diclofenac sodium. AAPS Pharm Sci Tech. 2010;11(3):1250-6.

23. Khan MZI, Stedul HP, Kurjakovic N. A pH-Dependent Colon-Targeted Oral Drug Delivery System Using Methacrylic Acid Copolymers. II. Manipulation of Drug Release Using Eudragit L100 and Eudragit S100 Combinations. Drug Dev Ind Pharm. 2000;26(5):549-54.
24. Wadher KJ, Kakde RB, Umekar MJ. Formulation and Evaluation of Sustained Release Matrix Tablets of Metformin Hydrochloride Using pH Dependent and $\mathrm{pH}$ Independent Methacrylate Polymers. British Journal of Pharmaceutical Research. 2011;1(2):29-45.

25. Jannat S, Al-Mausam MA, Sharmin F, Islam SMA, Reza MS. Formulation and Evaluation of Sustained Release Matrix Type Transdermal Film of Ibuprofen. Bangladesh Pharmaceutical Journal. 2012;15(1):17-21.

26. Bakde B, Chandewar A. Design, development and optimization of famotidine gastroretentive drug delivery system. Der Pharmacia Lettre. 2011;3(6):218-24.

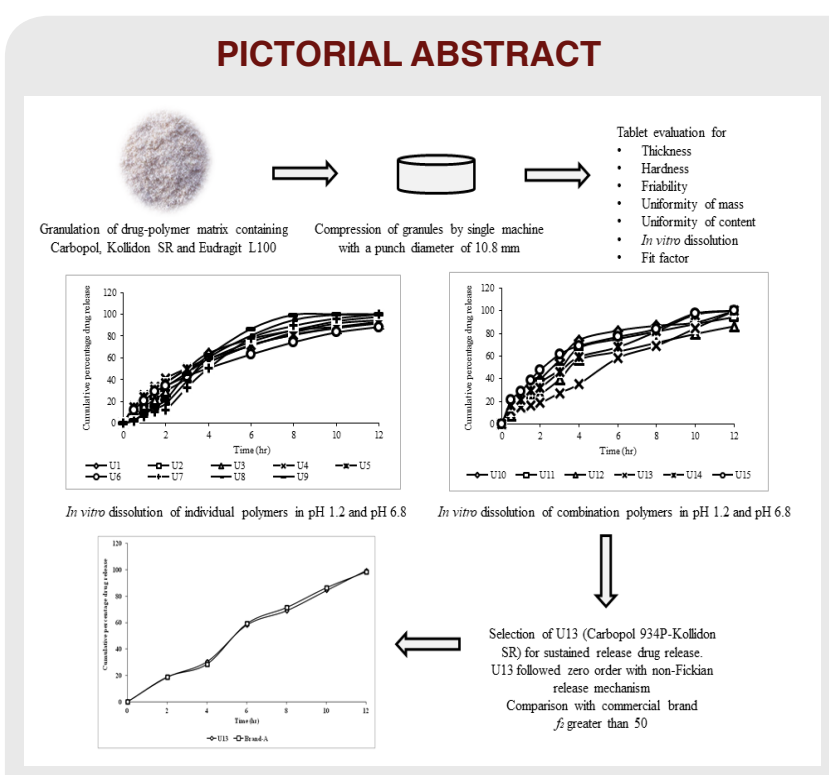

ABOUT AUTHORS

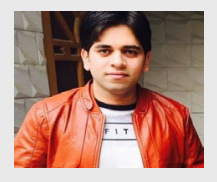

Uzair Nagra: PhD Scholar (Pharmaceutics, Faculty of Pharmacy, University of Lahore); Director Medisearch Pharma Pvt. Ltd. (Lahore, Pakistan).

\section{SUMMARY}

- The Aceclofenac tablets were prepared for sustained release drug profile using different percentages of Kollidon SR, Carbopol 934P and Eudragit L100 and their combination thereof. The tablets were analyzed for micromeritic properties and post compression studies including thickness, diameter, mechanical strength, uniformity of content. The in vitro dissolution studies were carried out in $\mathrm{pH} 1.2$ (initial $2 \mathrm{~h}$ ) and $\mathrm{pH} 6.8$ for 12 hrs. The tablets exhibited acceptable micromeritic properties and physical characteristics but tablets containing independent polymers had undesirable sustained release effects. Therefore, a combination of $\mathrm{pH}$ dependent polymer (Eudragit L100) with $\mathrm{pH}$ independent polymer (Carbopol 934P) and Carbopol 934P with plastic polymer (Kollidon SR) was used. The desired sustained release effect was given by latter combination at 2:1 concentration. This formulation, U13, followed zero order kinetics with non-Fickian drug release mechanism and had closer proximity to the marketed brand based on fit factor.

Cite this article: Nagra U, Adnan S, Shafqat S, Shabbir M, Ali S, Zafar A. Effect of Sustained Release Polymers on Drug Release Profile of Aceclofenac Tablets- Physicochemical Properties, Analysis of Kinetics and Fit Factor. Indian $\mathrm{J}$ of Pharmaceutical Education and Research. 2019;53(2S):s58-s65. 